\title{
Predicting the distribution of Stipa purpurea across the Tibetan Plateau via the MaxEnt model
}

Baibing $\mathrm{Ma}^{1,2}$ and Jian Sun ${ }^{1,3^{*}}$ (D)

\begin{abstract}
Background: The ecosystems across Tibetan Plateau are changing rapidly under the influence of climate warming, which has caused substantial changes in spatial and temporal environmental patterns. Stipa purpurea, as a dominant herbsage resource in alpine steppe, has a great influence on animal husbandry in the Tibetan Plateau. Global warming has been forecasted to continue in the future (2050s, 2070s), questioning the future distribution of S. purpurea and its response to climate change. The maximum entropy (MaxEnt) modeling, due to its multiple advantages (e.g. uses presence-only data, performs well with incomplete data, and requires small sample sizes and gaps), has been used to understand species environment relationships and predict species distributions across locations that have not been sampled.

Results: Annual mean temperature, annual precipitation, temperature seasonality, altitude, and precipitation during the driest month, significantly affected the distribution of S. purpurea. Only $0.70 \%$ of the Tibetan Plateau area included a very highly suitable habitat (habitat suitability $[\mathrm{HS}]=0.8-1.0$ ). Highly suitable habitat $(\mathrm{HS}=0.6-0.8$ ), moderately suitable habitat ( $H S=0.4-0.6$ ), and unsuitable habitat ( $H S=0.2-0.4$ ) occupied $6.20,14.30$ and $22.40 \%$ of the Tibetan Plateau area, respectively, and the majority (56.40\%) of the Tibetan Plateau area constituted a highly unsuitable habitat $(\mathrm{HS}=0-0.2)$. In addition, the response curves of species ecological suitability simulated by generalized additive model nearly corresponded with the response curves generated by the MaxEnt model.

Conclusions: At a temporal scale, the habitat suitability of S. purpurea tends to increase from the 1990s to 2050s, but decline from the 2050s to 2070s. At a spatial scale, the future distribution of S. purpurea will not exhibit sweeping changes and will remain in the central and southeastern regions of the Tibetan Plateau. These results benefit the local animal husbandry and provide evidence for establishing reasonable management practices.
\end{abstract}

Keywords: MaxEnt, Model simulation, Species distribution, Stipa purpurea, Tibetan Plateau

\section{Background}

During the last 100 years, global warming has caused substantial changes in spatial and temporal environmental patterns [1], especially in high-altitude regions [2], and these changes also determine the viability and

\footnotetext{
*Correspondence: sunjian@igsnrr.ac.cn; jian.sun@rutgers.edu ${ }^{1}$ Synthesis Research Centre of Chinese Ecosystem Research Network, Key Laboratory of Ecosystem Network Observation and Modelling, Institute of Geographic Sciences and Natural Resources Research, Chinese Academy of Sciences, 11A, Datun Roadm, Chaoyang District, Beijing 100101, China

Full list of author information is available at the end of the article
}

conservation of species [1]. As the world's third pole, Tibetan Plateau has a fragile vegetation that is vulnerable to climate change [2], and temperature and precipitation have been reported to be the main factors affecting the vegetation dynamic [3]. Furthermore, low temperature is taken as one of the most momentous limiting factors for the performance of alpine plants, whereas warming reinforces photosynthetic capacity and growth rates of these alpine plants $[4,5]$. In addition, both topographic (e.g. slope, aspect, altitude and so on) and soil (e.g. soil physical, chemical and biological properties) factors play a vital role in plant growth across Tibetan Plateau [6]. 
Stipa purpurea, a perennial grass species from the family poaceae, is widespread throughout the Tibetan Plateau [7]. As a dominant herbage resource in alpine steppe of the Tibetan Plateau, the production of S. purpurea has a great influence on animal husbandry on the Plateau [8]. S. purpurea steppe constitutes a horizontal zonation in the plains and vertical zonation on mountain slopes $[9,10]$. Due to its strong resistance to cold, drought and gale, $S$. purpurea can grow well in severe alpine environments, thus playing an important role in the preservation and stabilization of landscape diversity and heterogeneity [11]. Apart from preventing wind damage and regulating sand, S. purpurea conserves water and soil to preserve the stability of natural habitat [7]. However, S. purpurea as a plant species with one of the highest altitudinal distribution in the world is now suffering from global climate change and factitious disturbances [12]. The distribution of $S$. purpurea is affected not only by geographic location, but also by biological factors and natural and anthropogenic disturbances. Among abiotic disturbances, drought stress has drawn much attention because it is a main limiting factor for crop yield. The available soil water, which is largely determined by regional rainfall, affects plant growth, biomass accumulation, and leaf gas exchange rates [13].

Because of the concerns regarding the changing abiotic conditions in the Tibetan Plateau, there is an increasing interest in developing predictions to understand future communities. One tool to do this is species distribution modeling (SDM) which employs suitability indices. Suitability indices describe the relationship between habitat suitability score and a given environmental variable of a target species. Habitat suitability is a way to predict the suitability of habitat at a certain location for a given species or group of species based on their observed affinity for particular environmental conditions [14]. However, the ability to predict species distributions is highly dependent on the way in which the models are constructed, the quality, quantity, and availability of the records of true absence, and the distribution of present species, and the environmental predictor variables used to model the potential distribution of the species [15-17]. SDM depicts the relationships of different ecological variables and assesses habitat suitability for a given species. Climatic changes can affect the distribution of interacting species, which in turn may change the interactions [18]. However, species interactions may also affect climate change, for example, by changing community dynamics [19]. Understanding habitat suitability is thus critical for the development of long-term conservation strategies. Therefore, there is growing interest in understanding habitat suitability, species distributions, and habitat ecology for an improved environmental management across climates and terrestrial ecosystems [20,21].

There are many types of typical SDMs, such as MaxEnt [22], BIOCLIM [23], DOMAIN [24], generalized additive model (GAM) [25], GLM [26], and BIOMAPPER [27], et al. We selected maximum entropy (MaxEnt) modeling because of its multiple advantages: (1) it uses presence-only data and performs well with incomplete data; and (2) requires small sample size and allows gaps [28]. Using the current distribution data for S. purpurea and the present climate data, the present study aimed to predict the effects of future climate change on the distribution of $S$. purpurea across the Tibetan Plateau using the MaxEnt model. The objectives of this study were to: (1) model the influence of bioclimatic and topographic factors on species distribution patterns; and (2) discuss the change in habitat suitability distribution during three periods (the 1990s, 2050s and 2070s) in the Tibetan Plateau. The results will contribute to better understanding of the processes and mechanisms of adaptation and diffusion of biology under complex climate and environmental conditions and provide theoretical basis and guidance for the management of agriculture and animal husbandry in the region.

\section{Methods}

\section{Study area}

The Tibetan Plateau $\left(26^{\circ} 00^{\prime}-39^{\circ} 47^{\prime} \mathrm{N}, 73^{\circ} 19^{\prime}-104^{\circ} 47^{\prime} \mathrm{E}\right)$ is located in northwestern China. It is situated at extreme altitude, with an average elevation of over $4000 \mathrm{~m}$, and covers an area of approximately 2.58 million $\mathrm{km}^{2}$. Precipitation and temperature have clear regional distribution patterns, with annual precipitation increasing from roughly $50-700 \mathrm{~mm}$ from the northwest to the southeast, and annual temperature increasing gradually from - 15 to $20{ }^{\circ} \mathrm{C}$ from the northeast to the southeast [29]. The region is characterized by simultaneous heat and moisture, with a two distinct seasons, and the precipitation that diminishes from south to north and from east to west. Vegetation types from central to western Tibetan Plateau are alpine meadow, alpine steppe, alpine shrub grassland and desert grassland [30].

\section{Data compilation}

\section{S. purpurea data}

From July to mid-August in 2015, we conducted a multisite survey during the peak growing season in 11 counties: Geer, Gaize, Nima, Zhongba, Dingri, Anduo, Nagqu, Yushu, Maduo, Wulan and Daocheng. The surveyed species indices included vegetation coverage, density, and height within each quadrat $(0.5 \mathrm{~m} \times 0.5 \mathrm{~m})$, and the distribution of $S$. purpurea over the Tibetan Plateau was recorded from 80 specimens. Furthermore, 52 samples 


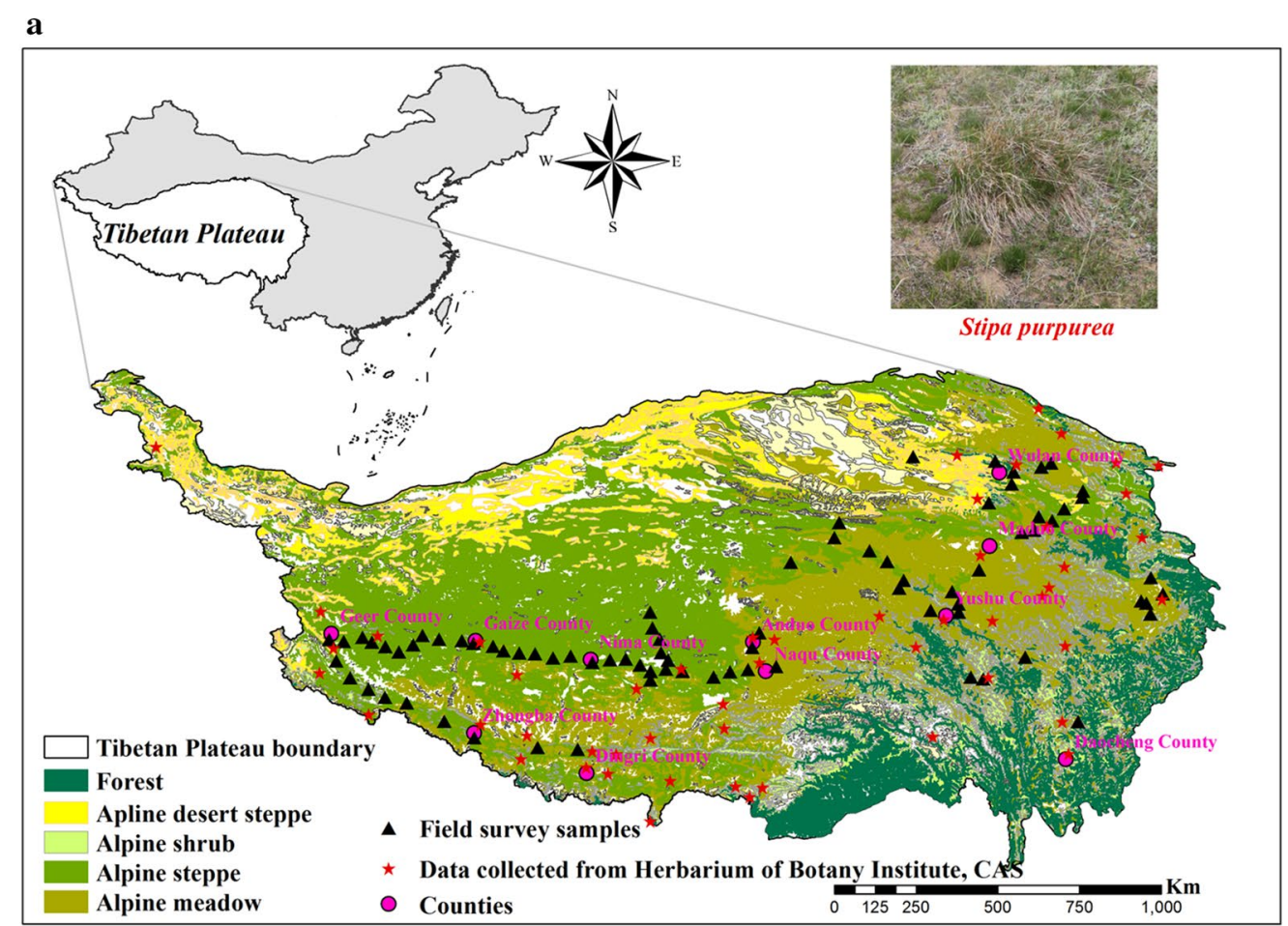

b

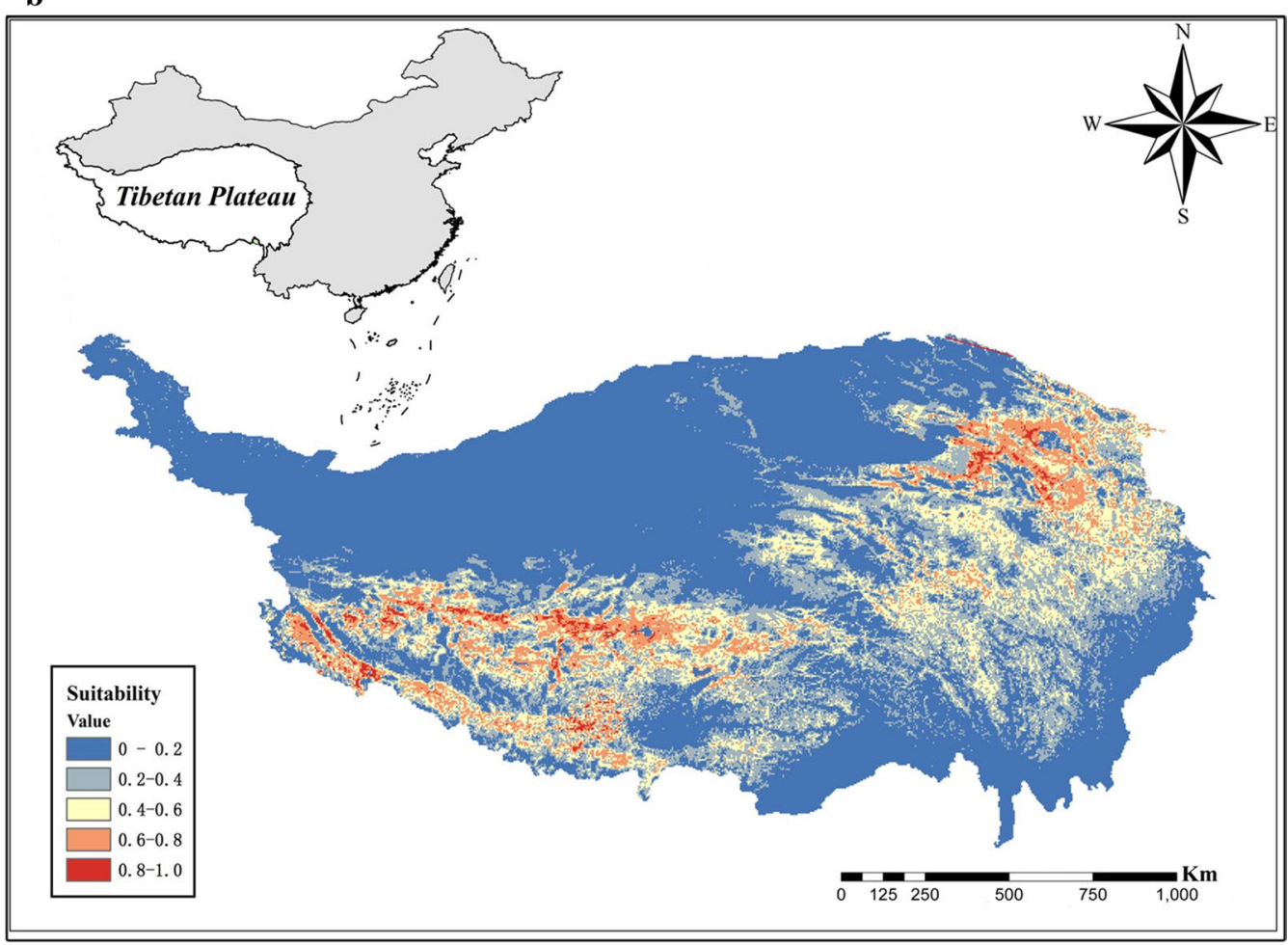

Fig. 1 The vegetation types of grasslands in Tibetan Plateau. The distribution point and source of S. purpurea in Tibetan Plateau.(S. purpurea I represents field survey sample; S. purpurea II represents Herbarium of Botany Institute, CAS; The Sample collection route stands for field survey roadmap in Tibetan Plateau) (a). Habitat suitability distribution of S. purpurea (b) 
were obtained from the Herbarium of Botany Institute at the Chinese Academy of Sciences. Figure 1a shows the detailed distribution of S. purpurea in the Tibetan Plateau (Additional file 1: Table S1). The datasets used and analysed during the current study available from the corresponding author on reasonable request.

\section{Environmental variables}

Bioclimatic variables are crucial in defining species' environmental niches. Data for 19 bioclimatic variables were downloaded from WorldClim-Global Climate Data (www.worldclim.org/bioclim), which included the current conditions (interpolations of observed data, representative of 1960-1990) and future conditions (the 2050s, 2070s), as well as the downscaled global climate model data from CMIP5 (IPCC Fifth Assessment Report, AR5). All environmental data used in this model had a 30 arcsecond spatial resolution (also referred to as $1 \mathrm{~km}$ spatial resolution). The topographic variables included slope, aspect and altitude. The altitude variable with $30 \mathrm{~m} \mathrm{spa-}$ tial resolution was downloaded from Geospatial Data Cloud (http://www.gscloud.cn/). The slope and aspect variables were calculated using ArcToolbox, Spatial Analyst, Surface Analyst in GIS 10.2 (Esri, Redlands, CA, USA).

Representative concentration pathways (RCPs) are four greenhouse gas concentration (not emissions) trajectories adopted by the Intergovernmental Panel on Climate Change (IPCC) in its AR5 in 2014 [31]. This supersedes the Special Report on Emissions Scenarios (SRES) projections published in 2000 [32]. These pathways are used in climate modeling and research to describe four possible future climates, all of which are considered possible depending on how many greenhouse gases are emitted in the near future. The four RCPs-RCP2.6, RCP4.5, RCP6, and RCP8.5-are named after a possible range of Radiative Forcing values in the year 2100 relative to pre-industrial values $(+2.6,+4.5,+6.0$, and $+8.5 \mathrm{~W} /$ $\mathrm{m}^{2}$, respectively) [33]. Here, we selected the RCP2.6 and RCP8.5 models to simulate habitat suitability distributions of S. purpurea in the 2050s and 2070s. MaxEnt output for habitat suitability distribution of the species were reclassified in GIS 10.2 (Esri, USA) with ArcToolbox, Spatial Analyst and Reclassify. To compare the changes in the area of suitable habitat in RCP2.6 from the 1990s to 2050 s, we used the ecological suitability index of 0.60 as the threshold to distinguish the stand or fall of the ecological suitability-values greater than 0.60 were defined as better suitability and less than 0.60 as poor suitability.

\section{Data analysis}

To establish a model that has better performance with fewer variables, we performed a correlation analysis and principal component analysis, and then screened eight bioclimatic variables (Table 1) to explore the response of $S$. purpurea to climate change. Only one variable from each set of highly cross-correlated variables $\left(\mathrm{r}^{2}>0.85\right.$; Fig. 2) was kept for further analysis [14]. These 19 bioclimate variables were extracted from the corresponding layers using ArcGIS 10.2 (Esri, USA). In addition, topographic variables altitude, slope and aspect were chosen to explore the response of $S$. purpurea to terrain factor change (Table 1).

The package mgcr in $\mathrm{R}$ language [34] was used to establish the GAM and verify the results of the MaxEnt model response curves for 11 environmental variables.

Table 1 The selected environment variables for modeling the habitat suitability distribution of S. purpurea

\begin{tabular}{|c|c|c|c|c|}
\hline Data source & Category & Variables & Abbreviations & Units \\
\hline \multirow[t]{3}{*}{ Geospatial data cloud } & Topographic & Altitude & DEM & m \\
\hline & & Slope & Slope & Degree \\
\hline & & Aspect & Aspect & Degree \\
\hline \multirow[t]{8}{*}{ WorldClim } & Bioclimatic & Annual mean temperature & Bio1 & ${ }^{\circ} \mathrm{C}$ \\
\hline & & Mean diurnal range (mean of monthly (max temp - min temp)) & $\mathrm{Bio} 2$ & ${ }^{\circ} \mathrm{C}$ \\
\hline & & Isothermality (B|O2/BIO7) $\left({ }^{*} 100\right)$ & $\mathrm{Bio3}$ & - \\
\hline & & Temperature Seasonality (standard deviation * 100) & Bio4 & ${ }^{\circ} \mathrm{C}$ \\
\hline & & Annual precipitation & Bio12 & $\mathrm{mm}$ \\
\hline & & Precipitation of driest month (3 months) & Bio14 & $\mathrm{mm}$ \\
\hline & & Precipitation seasonality (Coefficient of variation) & Bio15 & Fraction \\
\hline & & Precipitation of coldest quarter (3 months) & Bio19 & $\mathrm{mm}$ \\
\hline
\end{tabular}

Eight bioclimatic variables were selected from nineteen bioclimatic which downloaded from WorldClim-Global Climate Data (www.worldclim.org/bioclim). The altitude variable with $30 \mathrm{~m}$ spatial resolution was downloaded from Geospatial Data Cloud (http://www.gscloud.cn/). The slope and aspect variables were calculated using ArcToolbox-Spatial Analyst-Surface Analyst in GIS 10.2 

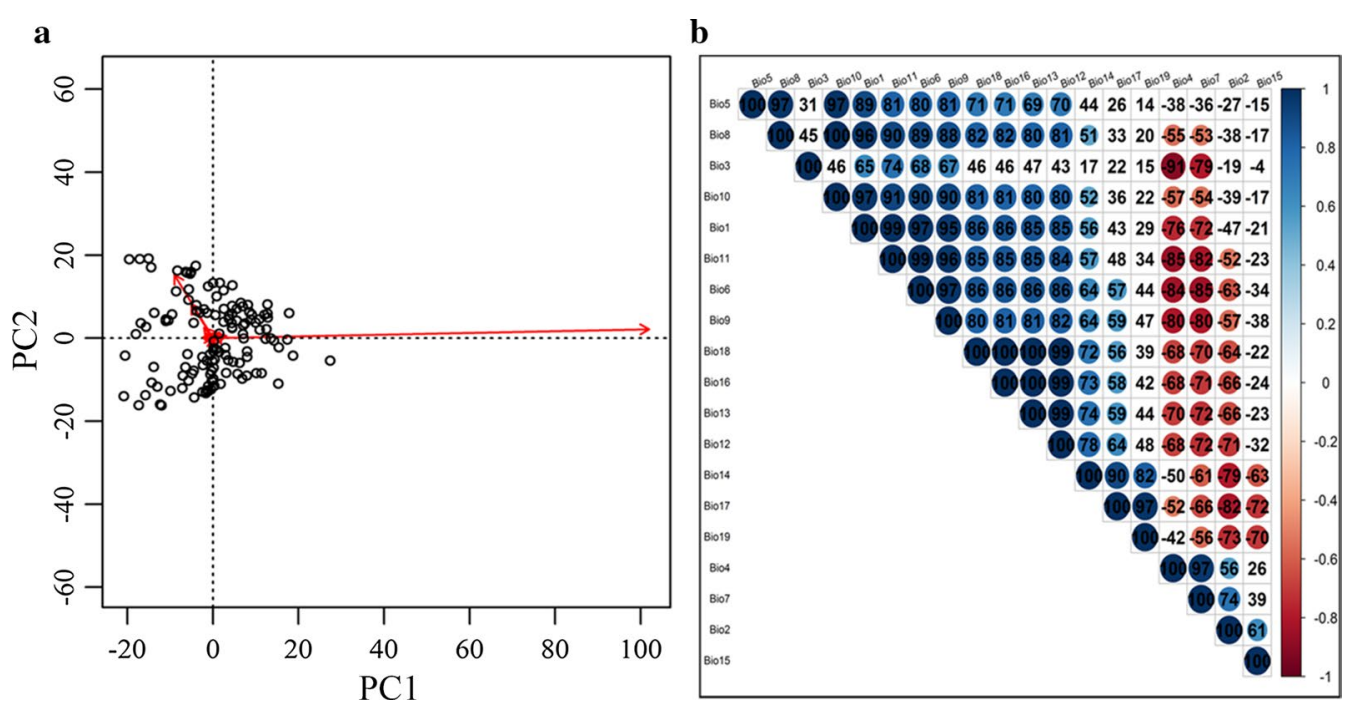

Fig. 2 The principal component analysis (PCA) of environmental variables (a). Correlation analysis of the independent variables (b), and the colored solid circles represent the significant correlation $(P<0.05)$

\section{Model simulation}

\section{Maximum entropy (MaxEnt) model}

The MaxEnt theory was proposed by Jaynes [35]. It allows a probability distribution of maximum entropy to be calculated for the modeled target based on a set of environment variables [22].

For a random variable $\lambda$ that has $\mathrm{n}$ different potential results $\mathrm{X}_{1}, \mathrm{X}_{2}, \ldots \mathrm{X}_{\mathrm{n}}$, for which the occurrence probabilities are $P_{1}, P_{2}, \ldots P_{n}$, respectively, the entropy of $\lambda$ is given by the formula [14]:

$$
\mathrm{H}(\lambda)=\sum_{\mathrm{i}=1}^{\mathrm{n}} \mathrm{P}_{\mathrm{i}} \log \frac{1}{\mathrm{P}_{\mathrm{i}}}=-\sum_{\mathrm{i}=1}^{\mathrm{n}} \mathrm{P}_{\mathrm{i}} \log \mathrm{P}_{\mathrm{i}}
$$

The MaxEnt theory can be employed to predict species habitat suitability as follows. If we know nothing about local ecological conditions or a species' life habits, the most practical prediction is that the probabilities that the area is either suitable or not for the species are both 0.5. Any data that indicate that species is present within a set of local ecological conditions is information that will reduce the uncertainty of a MaxEnt model. The more information is available, the more the uncertainty is reduced. The MaxEnt method is used to establish a model with the maximum entropy consistent with available knowledge [36]. We established the models with MaxEnt modeling version3.3.3k, which can be downloaded free from http://www.cs.princeton.edu/.

The receiver operating characteristic (ROC) describes corresponding values for omission error (FPR-horizontal axis) and sensitivity (TPR - vertical axes), with one point for each unique threshold value. The area under the ROC (AUC) was used as the MaxEnt predictive performance metric under the ROC curve. AUC values, which were obtained for both the training and evaluation data sets, are named training and testing AUC, respectively [37]. AUC values are used generally for qualitative characterization of distribution models. Araújo et al. [38] expanded a model evaluation index to "fail" for $0.50<$ AUC $<0.60$, "poor" for $0.60<$ AUC $<0.70$, "fair" $0.70<$ AUC $<0.80$, "good" $0.80<$ AUC $<0.90$, and "excellent" for $0.90<\mathrm{AUC}<1.00$. The AUC of the ROC plot for test localities $\left(\mathrm{AUC}_{\text {test }}\right)$ can be used as the basis for MaxEnt model tuning of the settings [39]. Higher values reflect better ability of the model to discriminate between conditions at withheld (testing) occurrence localities and those at background localities (by ranking the former higher than the latter based on their predicted suitability values) [40].

Many recent studies have shown that the current default settings in MaxEnt were based on an extensive empirical tuning study, which can result in poorly performing models $[41,42]$. For the original predictor variables ('feature class' or FC), allowing more FC enables more flexible and complex fits to the observed data. Users can specify which FC will be allowed, and adjust the level of regulation multiplier ( $R M$; default $=1.0$ ). However, higher flexibility can increase the propensity for model overfitting. We built models with RM values ranging from 0 to 4 (increments of 0.5 ) and with six different FC combinations (L, LQ, H, LQH, LQHP, LQHPT; where $\mathrm{L}=$ linear, $\mathrm{Q}=$ quadratic, $\mathrm{H}=$ hinge, $\mathrm{P}=$ product and $\mathrm{T}=$ threshold). In the present study, we used the 
method of collecting samples and sample information to predict the distribution of S. purpurea.

\section{Model verification method}

The flexibility of the GAM enables to predict the functional form of the appropriate variable. As an exploratory tool, the smoothing and additive models are of high value, and many environmental and ecological studies used the fitted additive model as the final model [43].

Because S. purpurea is affected by both biological and abiotic environmental variables, the relationship between its spatial distribution and a particular environmental variable is not always linear. Therefore, a proper parametric method should be implemented when examining the relationships between ecological suitability of $S$. purpurea's and environmental variables.

We used GAM to verify the outputs of MaxEnt. In ArcGIS10.2 (Esri, USA), we selected transects of environmental variables and extracted each environmental variable to construct the model. The selected transects are given in the supporting information (Additional file 2: Figure S1, S2 and S3). The model can be expressed as:

$$
\mathrm{G}(\mathrm{MUY})=\alpha_{0}+\mathrm{f}_{1}\left(\mathrm{x}_{1}\right)+\cdots \cdot+\mathrm{f}_{\mathrm{n}}\left(\mathrm{x}_{\mathrm{n}}\right)+
$$

where MUY is the expectancy value of $Y, G(M U Y)$ is copula, $\alpha_{0}$ is the intercept, in $f_{n}\left(x_{n}\right), f_{n}(\cdots)$ is the singlevariable function used to explain variable $\mathrm{x}_{\mathrm{n}}$ and $\varepsilon$ is the random variable.

Before analyzing the relationship between ecological suitability and an individual variable, the normal $\mathrm{Q}-\mathrm{Q}$ should be used, and the copula can be determined based on a roughly normal distribution of ecological suitability. Here, identity link: $g(z)=z$ was selected as the copula. Through correlation analysis and principal component analysis, we selected 11 environmental variables that are thought to be uncorrelated or have little relationship.

\section{Results \\ Model training \\ Model performance and contribution of environmental variables}

The outputs of $\mathrm{AUC}_{\text {test }}$ were significantly different under different model settings (Fig. 3a). The variable FC showed greater difference at the equal level of RM, whereas the variable RM presented little difference at the equal level of $\mathrm{FC}$. For $\mathrm{FC}=\mathrm{LQHPT}$ and $\mathrm{RM}=0.5$, the value of $\mathrm{AUC}_{\text {test }}$ reached the maximum, indicating that MaxEnt can perform well.

The ROC estimate showed that the AUC values of the training and test data-sets were 0.901 and 0.937 , respectively, which revealed a high level of accuracy in the model prediction (Fig. 3b).
The results of the jackknife test of the variables' contribution to the model are shown in Fig. 3c. Among the 11 environmental variables used to establish the model, annual mean temperature (Bio1) and annual precipitation (Bio12) had very high weights when used independently, whereas temperature seasonality (Bio4), altitude and precipitation during the driest month (Bio14) had moderate weight when used separately, indicating that these variables could affect the habitat suitability distribution of $S$. purpurea. The other variables, including isothermality (Bio3), slope, precipitation seasonality (Bio15), mean diurnal temperature range (Bio2) and aspect, showed low weight and thus indicated poor influence on the habitat suitability distribution of $S$. purpurea.

\section{Response of habitat suitability to environmental variables}

Response curves showed the quantitative relationship between the logistic probability of the presence and environmental variables, and deepened the understanding of the ecological niche of the species by illustrating the responses of 11 variables to $S$. purpurea suitability (Fig. 4a). Based on the response curves, the suitable annual mean temperature (Bio1) ranged from -3 to $5{ }^{\circ} \mathrm{C}$ which demonstrated that the optomal environmental temperature for growth of $S$. purpurea's was low. The response curves of Bio2 showed that from 14 to $15^{\circ} \mathrm{C}$ was the suitable annual mean temperature range. However, Bio2 did not influence the habitat suitability significantly. The optimal isothermality (Bio3), which is defined by the ratio between $\mathrm{Bio} 2$ and $\mathrm{Bio} 7$ and reflects the regional temperature fluctuation, for eco-suitability was approximately 0.40 .

Greater seasonality reflects greater variability in temperature, which is illustrated by temperature seasonality Bio4 as the degree of temperature variation over a given period. The response curve for Bio4 showed that the highest probability of S. purpurea presence was associated with areas in where the temperature seasonality values ranged from 70 to 95 . In addition, based to the response curve for precipitation during the driest month (Bio14), the suitable precipitation in the driest month was under $0 \mathrm{~mm}$, which further confirmed that $S$. purpurea is drought resistant.

Based on the response curves for altitude and slope, the suitable altitude for the species is from 4200 to $4800 \mathrm{~m}$ at the slope greater than $70^{\circ}$.

\section{Relationship between habitat suitability for S. purpurea's and environmental Variables}

GAM confirmed the relationship between the response variable (habitat/ecological suitability) and explanatory variable (environmental variable) (Fig. 4b). With respect to Bio1, the eco-suitability increased as temperature 


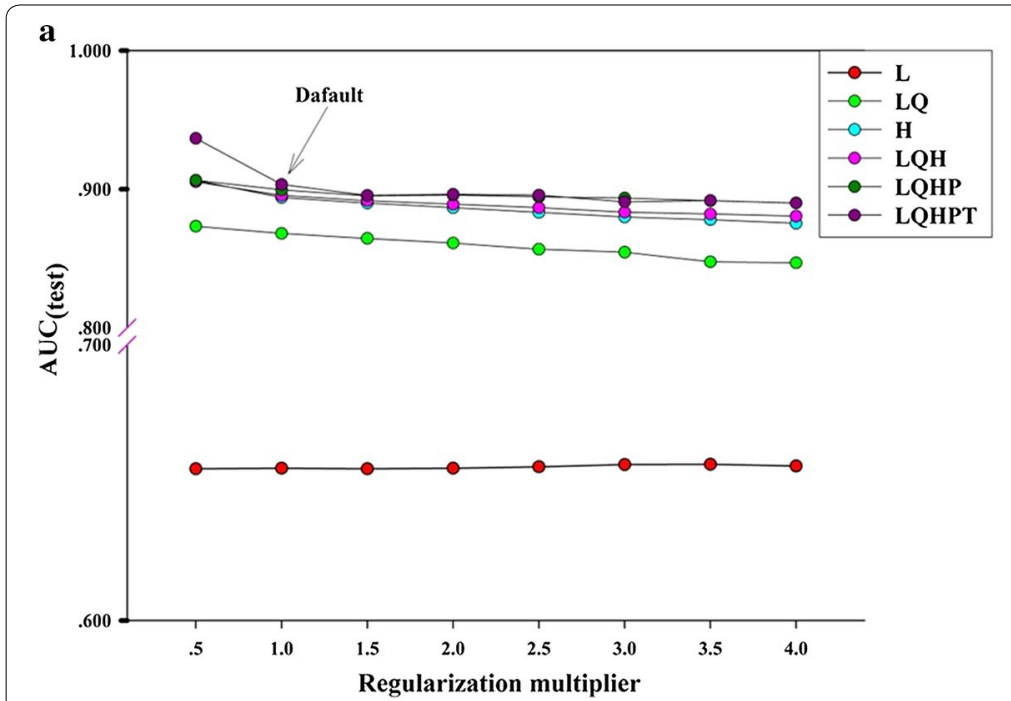

b

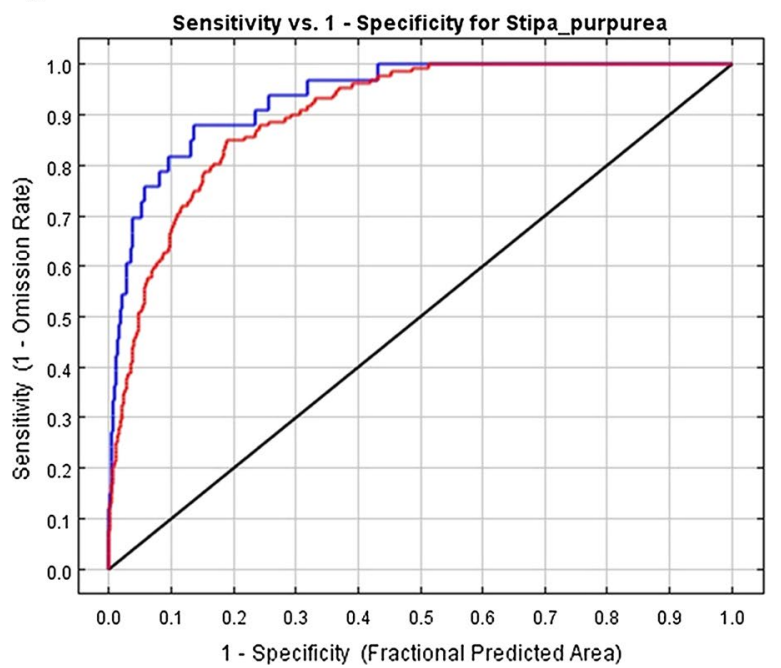

c

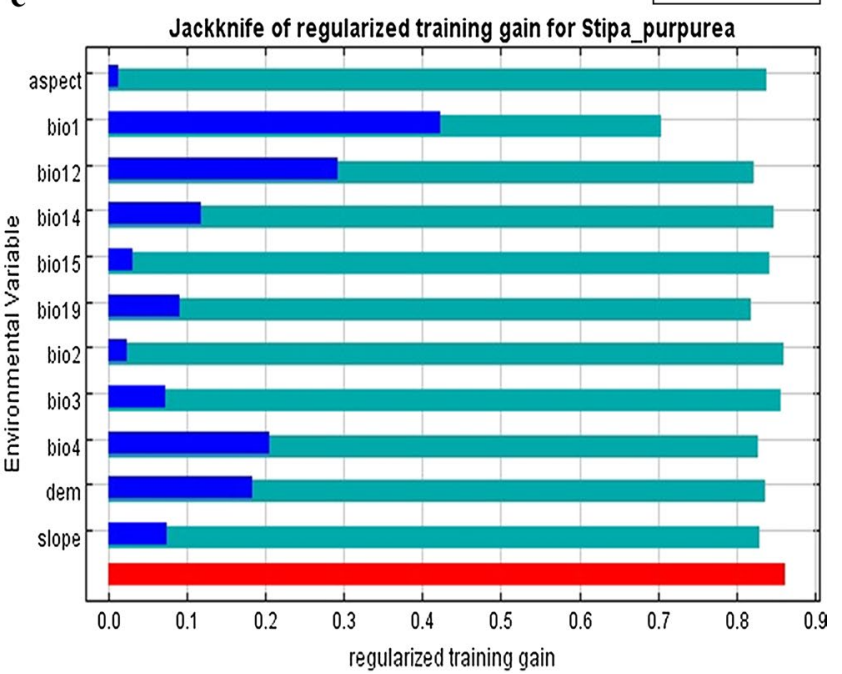

Fig. 3 a Shows the value of $A \cup C_{\text {test }}$ in different MaxEnt model settings $(L=$ linear, $Q=$ quadratic, $H=$ hinge, $P=$ product and $T=$ threshold). b Represents the results of the AUC (area under ROC) curves in developing S. purpurea habitat suitability model. c Represents the results of the jackknife test of variables' contribution in modeling $S$. purpurea habitat suitability distribution

increased from -15 to $0{ }^{\circ} \mathrm{C}$ and decreased when the temperature was greater than $0{ }^{\circ} \mathrm{C}$. The results followed a normal distribution, with the most appropriate temperature ranging from -3 to $3{ }^{\circ} \mathrm{C}$. With respect to mean diurnal temperature range (Bio2), the response curve conformed approximately with the MaxEnt output. The isothermality (Bio3) in the range from 0.35 to 0.40 revealed that GAM reflected the optimal change in eco-suitability at 0.37 . The ecologically suitable range of annual precipitation (Bio12) for the species was from 200 to $800 \mathrm{~mm}$ but it was very low as the precipitation exceeded $1000 \mathrm{~mm}$. The ecological suitability declined at first and then recovered for precipitation of the direst month (Bio14). The minimum value of the precipitation seasonality (Bio15) was close to 0.70 . In terms of environmental variables Bio1-Bio4, Bio12, Bio14 and Bio15, the trends of the response curves were in harmony with the outputs from the MaxEnt analysis. However, there was a significant difference in the response curve for precipitation of the coldest quarter (Bio19). The MaxEnt results showed that the eco-suitability increased with increasing Bio19. 

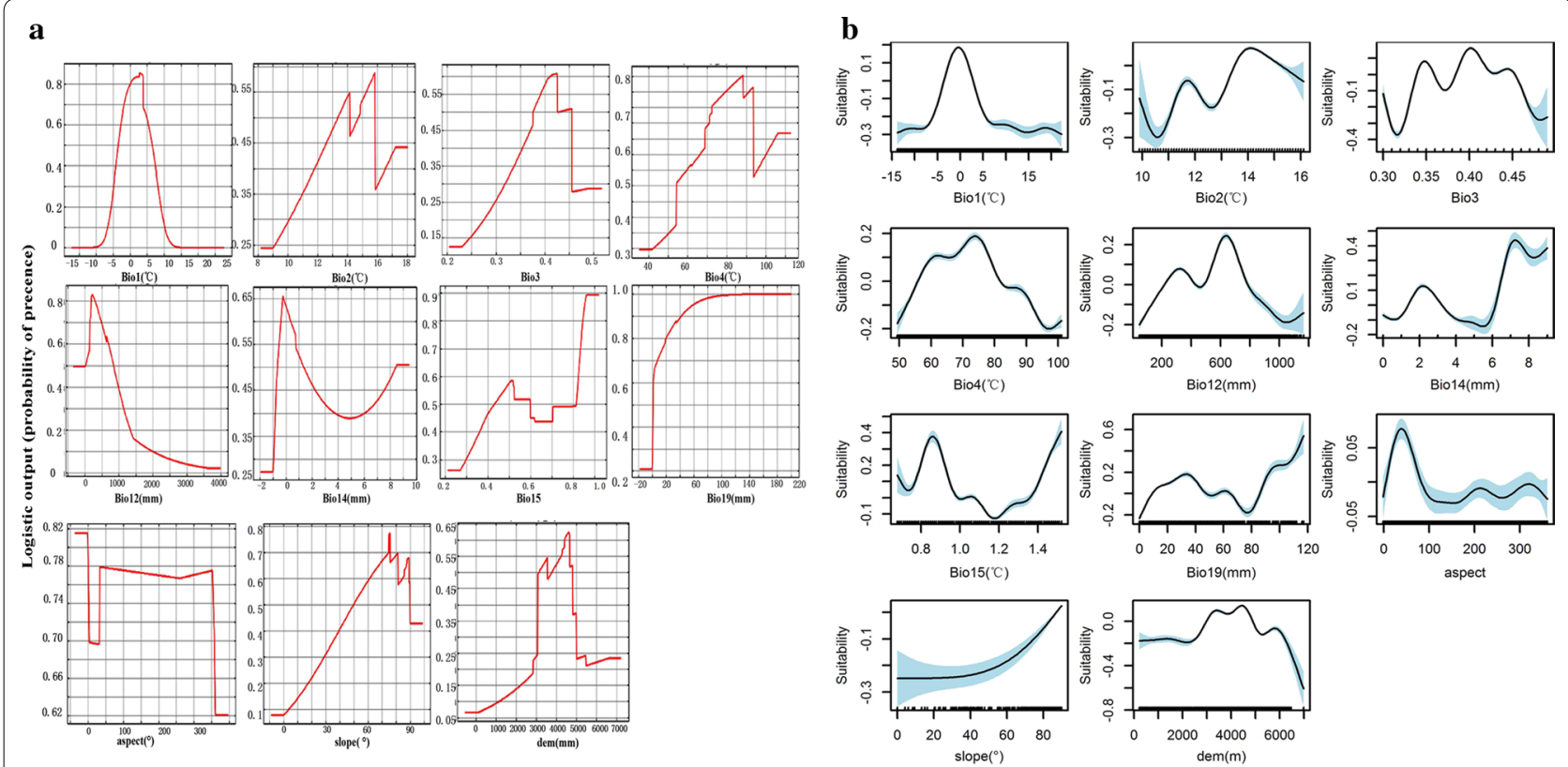

Fig. 4 a Describes the response curves of 11 environmental variables in S. purpurea habitat distribution model. b Describes the MaxEnt verification results based on Generalized Additive Model (GAM)

The analysis of the response curves of the terrain variables aspect, slope, and altitude had similar curves with the modeling results of MaxEnt; the most suitable elevation for the species was estimated at $3000-5000 \mathrm{~m}$. The simulations of the relationship between the response and explanatory variables using the GAM were consistent with the results obtained by MaxEnt. The AUC values of the training (0.901) and test (0.937) data-sets also indicated that the MaxEnt model was reliable in analyzing the distribution of $S$. purpurea across the Tibetan Plateau.

\section{Distribution and prediction of S. purpurea Distribution of S. purpurea}

The predicted habitat suitability was divided into five probability classes (Fig. 1b): 0-0.20 represented highly unsuitable habitat, $0.20-0.40$ was unsuitable habitat, 0.40-0.60 indicated moderately suitable habitat, 0.600.80 was highly suitable habitat, and $0.80-1.00$ indicated very highly suitable habitat. Only $0.70 \%$ of the area could be considered a very highly suitable habitat, followed by highly suitable habitat $(6.20 \%)$; moderately suitable habitat $(14.30 \%)$, and unsuitable habitat $(22.40 \%)$. The greatest percentage $(56.40 \%)$ of the Tibetan Plateau area was classified as highly unsuitable habitat. The loading of the suitability, altitude, annual mean temperature (Bio1) and annual precipitation (Bio12) layer into ArcGIS10.2 (Esri, USA) revealed that among these suitability classes, the highly suitable habitat was found only in the midlands and the northeast side of the study area, where the annual mean precipitation ranged from 0 to $899 \mathrm{~mm}$, annual mean temperature was from -3.1 to $3.8^{\circ} \mathrm{C}$, and altitude ranged from 3806 to $5654 \mathrm{~m}$.

\section{Predicting the distribution of S. purpurea}

The habitat suitability distributions of $S$. purpurea's in the 2050s and 2070s were shown in Fig. 5a-d. Generally, the habitat suitability of S. purpurea in RCP2.6 and RCP8.5 revealed that habitat suitability for the species increased from the 1990s to 2050s, then decreased from the 2050s to $2070 \mathrm{~s}$. Figure $5 \mathrm{e}, \mathrm{f}$ illustrated that the change in the distribution of $S$. purpurea under the two scenarios in the 1990s, 2050s and 2070s. The comparison of the RCP2.6 scenario between the 2050s and 1990s and between the 2070s and 1990s revealed an increase suitable area of $3739 \mathrm{~km}^{2}$ in the 2050s and an increase of $193 \mathrm{~km}^{2}$ in the 2070s, which illustrated that in the RCP2.6 scenario, the future distribution of suitable habitat for S. purpurea will increase with increasing temperature. The comparison of the RCP8.5 scebario between the 2050s and 1990s and between the 2070s and 1990s revealed greater amplitude of variation than that observed for RCP 2.6; an increase in suitable area with a value of $5076 \mathrm{~km}^{2}$ was predicted in the 2050s, but a decrease with a value of $113 \mathrm{~km}^{2}$ was predicted for the 2070s. This suggested that the greater change in temperature the more obvious effect could be 


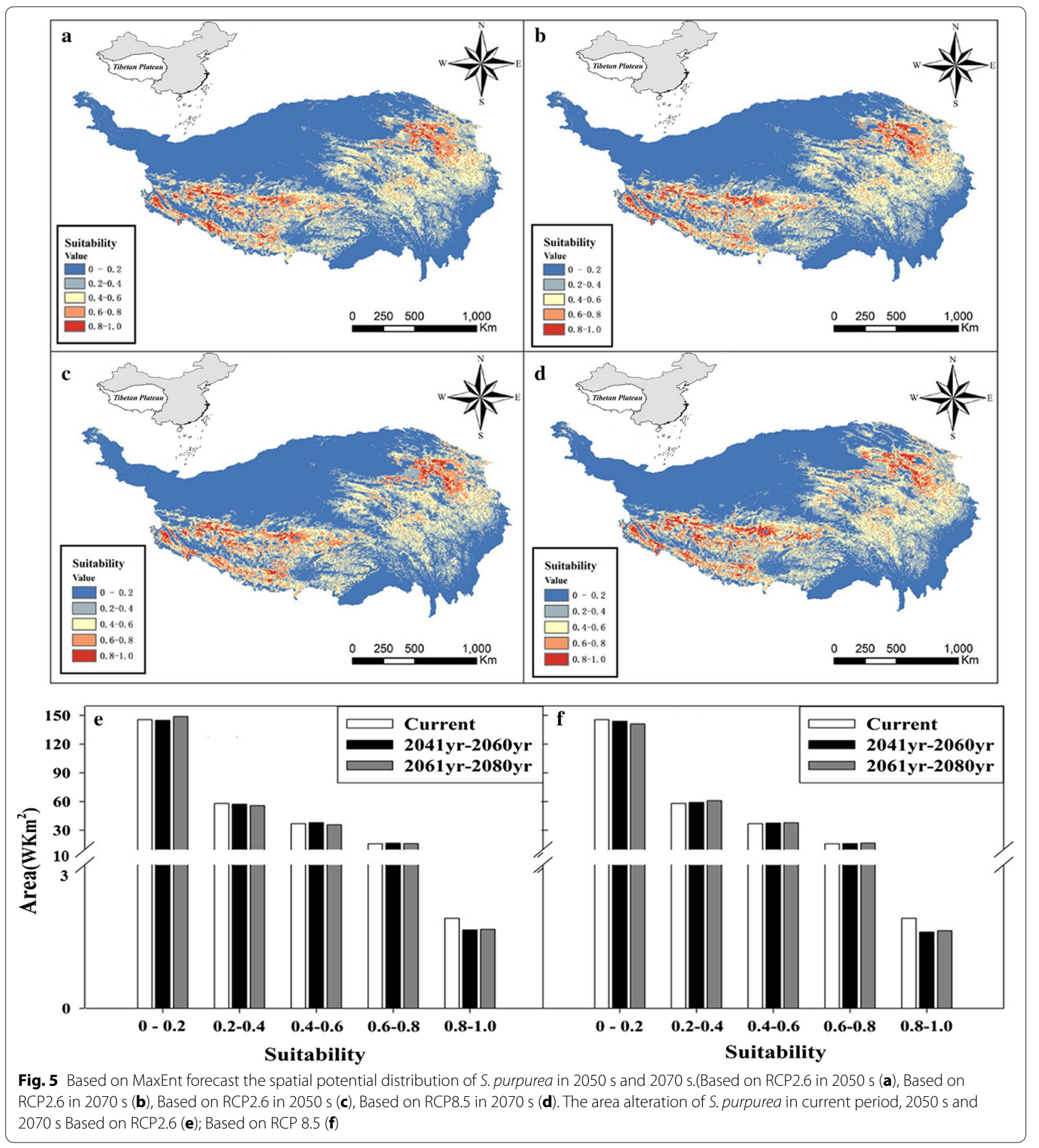

found on the distribution of S. purpurea. Taken together, these results suggested that suitable habitat for S. purpurea will increase from the 1990s to 2050s and then decline from the 2050s to 2070s.

\section{Discussion}

Relationship between S. purpurea's habitat suitability and environmental variables

Among the 11 environmental variables adopted in the model, annual mean temperature (Bio1) and annual precipitation (Bio12) were the most important contributors to 
habitat suitability distribution of S. purpurea as indicated by their high weighs when used independently. Hence, precipitation and temperature are important environmental factors that affect plant growth and distribution [44]. The optimal environmental temperature for growth of $S$. purpurea is low $\left(-3\right.$ to $\left.5{ }^{\circ} \mathrm{C}\right)$, as indicated by Biol response curve. Some studies indicated that S. purpurea is a plant adapted to semiarid alpine cold meadow or alpine steppe where the mean annual temperature is approximately $-1.5^{\circ} \mathrm{C}$ [45]. Rainfall is one of the most significant factors in shaping the function and structure of plants and terrestrial ecosystems on the Tibetan Plateau [13] and the suitable annual mean precipitation is at most $1000 \mathrm{~mm}$ for growth of $S$. purpurea. Besides, temperature seasonality (Bio4), altitude and precipitation during the driest month (Bio14) also have an effect on the habitat suitability distribution of S. purpurea. The response curve for precipitation seasonality showed that the greater precipitation seasonality increased the probability that $S$. purpurea was present at a location. In the coldest season, rise of precipitation increased habitat suitability for S. purpurea. Wang et al. [46] also found that temperature is an important climatic factor for growth of plants in semiarid or arid regions. Based on the response curves of DEM, suitable altitude for S. purpurea is between 4200 and $4800 \mathrm{~m}$, which corresponds to the altitude range of the alpine grassland distribution from 4500 to $4800 \mathrm{~m}$ [45]. Continuous pressure from environmental stresses promotes plant adaptation and evolution of numerous mechanisms for survival under adverse conditions [47]. Thus, the relatively higher percentage of fats and soluble sugars in seeds at higher altitude might provide enough energy for seed germination and initial growth of seedlings, thereby enhancing the ability of seedlings to resist harsh environmental conditions [48]. Seed germination and subsequent seedling growth are directly related to population regeneration and community formation. The seeds of $S$. purpurea by raising its growth rate compensate for this competitive disadvantage, which guarantees early development and growth of S. purpurea in high altitude regions [49].

The other variables, such as isothermality (Bio3), slope, precipitation seasonality (Bio15), mean diurnal temperature range (Bio2) and aspect, have little influence on the habitat suitability distribution of $S$. purpurea. In terms of the effects of rainfall on plant growth, Zhang et al. [50] concluded that precipitation changes in a growing season affect the plant growth of plants and primary productivity. There was a significant difference in response curve for precipitation in the coldest season (Bio19) between MaxEnt and GAM results. According to the MaxEnt analysis, the eco-suitability increased as Bio19 increased, whereas the GAM results indicated that the eco-suitability increased and then decreased with increasing Bio19. A trend of increased overall temperature and humidity has been detected in Tibetan Plateau in recent years, which is conducive to the growth of grassland vegetation [51]. Therefore, the response curve of ecological suitability habitat and Bio19 inferred from the MaxEnt analysis reflect better the growth conditions of S. purpurea. Vegetation usually starts to grow when the temperature rises above $0{ }^{\circ} \mathrm{C}$. However, a lag of 1-2 months between vegetation growth and precipitation [44] suggested that that small amounts of rain affect plant habitat suitability in the coldest season. The response curves for slope revealed that most of the sampled specimens were found on slope greater than $70^{\circ}$. The reason for such unusually steep slopes is that, due to high altitude of the Tibetan Plateau, the spatial resolution of $30 \mathrm{~m}$ used by remote sensing to obtain the slope effect could not reflect the actual terrain of the Plateau.

\section{Changes in distribution of $S$. purpurea in the future}

From the perspective of the overall ecological suitability of $S$. purpurea, the proportions of highly suitable habitat and very highly suitable habitat are 6.20 and $0.70 \%$, respectively. Global warming promotes vegetation growth $[5,52,53]$, and a simulation of the warming climate in the alpine meadow area of the Tibetan Plateau revealed that temperature had a positive effect on alpine steppe by accelerating the process of alpine phenology and prolonging the growing season. However, a continuous rise in temperature had a negative effect on vegetation $[54,55])$. In the RCP8.5 scenario, the suitability of the overall landscape and the areas with habitats suitable for survival of $S$. purpurea' was higher than that in RCP2.6. S. purpurea is distributed in the central and southeastern regions of the Tibetan Plateau, and from the large spatial scale perspective, the future distribution of $S$. purpurea will not exhibit sweeping changes. Future growth conditions of S. purpurea will have a great impact on the livestock husbandry of Tibetan Plateau and on the modulation and improvement of the ecosystems on Tibetan Plateau and even Eurasian continent [13].

Apart from the above environmental factors, some other factors could also influence plant suitable habitats. Duan et al. [56] reported that overgrazing and excessive reclamation accelerate large-scale grassland degradation on the Tibetan Plateau. Significant decrease in grassland productivity and biological diversity has becoming a great obstacle to sustainable social economic and ecological development. Human activities including livestock overgrazing, yak trampling, and sod removal for construction, have created huge areas of "black soil" (also known as black soiltype degraded grassland). The sod layer, which is from 10 to $15 \mathrm{~cm}$ deep, is totally removed by intensive grazing and activities of rodents leaving the sub-soil uncovered [57]. In addition, unsustainable land use practices have resulted in 
great reduction of soil organic carbon and a rapid decline of soil fertility and crop productivity [58]. Once degraded, these eco-systems cannot be restored easily [59]. Therefore, our future study will focus on the effects of human activities on the distribution of $S$. purpurea.

\section{Conclusions}

Estimating how the future distribution of S. purpurea will respond to rapid environmental climatic modifications is of vital importance for determining the viability and conservation of S. purpurea. The results indicated that on a temporal scale, the suitable habitat for $S$. purpure tend to increase from the 1990s to 2050s and then decline from the 2050s to 2070s. On a spatial scale, the future distribution of S. purpurea will not experience sweeping changes, and the main distribution areas of the species will remain in the central and southeastern regions of the Tibetan Plateau. Our results will benefit the local animal husbandry and provide evidence for establishing reasonable management practices.

\section{Additional files}

Additional file 1: Table S1. Description of the sampled sites (Stipa purpurea) across Tibetan Plateau.

Additional file 2. The belt transects of environmental variables were chosen to construct GAM model. Figure S1. The belt transects of bioclimatic variables including annual mean temperature (Bio1), mean diurnal range (Bio2), isothermality (Bio3) and temperature seasonality (Bio4), respectively. Figure S2. The belt transects of bioclimatic variables including annual precipitation (Bio12), precipitation of driest month (Bio14), precipitation seasonality (Bio15) and precipitation of coldest quarter (Bio 19), respectively. Figure S3. The belt transects of topographic variables including aspect, slope and DEM, respectively.

\begin{abstract}
Abbreviations
RCPs: representative concentration pathways; MaxEnt: maximum entropy; SDMS: species distribution models; ROC: receiver operating characteristic; Bio1: annual mean temperature; Bio2: mean diurnal range (mean of monthly (max temp - min temp)); Bio3: isothermality ([BIO2/BIO7] × 100); Bio4: temperature seasonality (standard deviation $\times 100$ ); Bio12: annual precipitation; Bio 14: precipitation in the driest month; Bio15: precipitation seasonality (Coefficient of variation); Bio 19: precipitation in the coldest season.
\end{abstract}

\section{Authors' contributions}

IS carried out field experiments; IS collected samples in Tibetan Plateau; BM analyzed the results. BM and JS wrote the manuscript. Both authors read and approved the final manuscript.

\section{Author details}

${ }^{1}$ Synthesis Research Centre of Chinese Ecosystem Research Network, Key Laboratory of Ecosystem Network Observation and Modelling, Institute of Geographic Sciences and Natural Resources Research, Chinese Academy of Sciences, 11A, Datun Roadm, Chaoyang District, Beijing 100101, China. ${ }^{2}$ School of Earth Science and Resource, Chang'an University, Xi'an 710000 China. ${ }^{3}$ Department of Ecology, Evolution, and Natural Resources, Grant F. Walton Center for Remote Sensing \& Spatial Analysis, School of Environmental and Biological Sciences, Rutgers University, New Brunswick, NJ 08901, USA.

\section{Acknowledgements}

We would like to thank the Dr. Xiaojing Qin and Tiancai Zhou for the field investigation and the data collection.

\section{Competing interests}

The authors declare that they have no competing interests.

\section{Availability of data and materials}

The datasets used and analysed during the current study available from the corresponding author on reasonable request.

\section{Consent for publication}

Not applicable.

\section{Ethics approval and consent to participate} Not applicable.

\section{Funding}

This research was supported by the State Key Research Development Program of China (Grant Nos. 2016YFC0501802, 2016YFC0501803, 2016YFC0502002), the Natural Science Foundation of China (Grant No. 41501057), the Construction Service Program for Cultivating Feature Institution of the Chinese Academy of Sciences (TSYJS05), and Youth Innovation Research Team Project (LENOM2016Q0003)

\section{Publisher's Note}

Springer Nature remains neutral with regard to jurisdictional claims in published maps and institutional affiliations.

Received: 26 June 2017 Accepted: 10 February 2018

Published online: 21 February 2018

\section{References}

1. Hughes L. Biological consequences of global warming: is the signal already apparent? Trends Ecol Evol. 2000;15(2):56-61.

2. Sun J, Qin XJ, Yang J. The response of vegetation dynamics of the different alpine grassland types to temperature and precipitation on the Tibetan Plateau. Environ Monit Assess. 2016;188:5-25. https://doi. org/10.1007/s10661-015-5014-4.

3. Sun J, Cheng GW, Li WP. Meta-analysis of relationships between the environmental factors and the aboveground biomass in alpine grassland, Tibetan Plateau. Biogeosciences. 2013;10:1707-15. https://doi. org/10.5194/bg-10-1707-2013.

4. Li N, Wang GX, Yang Y, Gao YH, Liu GS. Plant production, and carbon and nitrogen source pools, are strongly intensified by experimental warming in alpine ecosystems in the Qinghai-Tibet Plateau. Soil Biol Biochem. 2011;43(5):942-53.

5. Xu MH, Peng F, You GG, Guo J, Tian XF, Xue X, Liu M. Year-round warming and autumnal clipping lead to downward transport of root biomass, carbon and total nitrogen in soil of an alpine meadow. Environ Exp Bot. 2015;109(109):54-62.

6. Sun J, Cheng GW, Li WP, Sha YK, Yang YC. On the variation of NDVI with the principal climatic elements in the Tibetan Plateau. Remote Sens. 2013;5:1894-911. https://doi.org/10.3390/rs5041894.

7. Liu WS, Zhao Y, You JL, Qi DH, Zhou Y, Chen JK, Song ZP. morphological and genetic variation along a north-to-south transect in Stipa purpurea, a dominant grass on the Qinghai-Tibetan Plateau: implications for response to climate change. PLoS ONE. 2016;11(8):e0161972.

8. Hu ZJ, Zhang YL \& Yu HB. Simulation of Stipa purpurea distribution pattern on Tibetan Plateau based on MaxEnt model and GIS. Chin J Appl Ecol. 2015;12:505-11.

9. Wang J. Main types and characteristics of high-cold steppe in the Qiangtang Plateau of XiZang. Acta Phytoecologica et ceobotanica sinica. 1982;6(1):1-13.

10. Zheng D. On the natural zonation in the Qinghai-Xizang Plateau. Acta Geographica Sinica. 1979;34(1):1-11.

11. Liu WS, Dong M, Song ZP, Wei W. Genetic diversity pattern of Stipa purpurea populations in the hinterland of Qinghai-Tibet Plateau. Ann Appl Biol. 2009;154:57-65. 
12. Liu W, Liao H, Zhou Y, Zhao Y, Song Z. Microsatellite primers in Stipa purpurea (Poaceae), a dominant species of the steppe on the QinghaiTibetan Plateau. Am J Bot. 2011;98:150-1.

13. Yang YQ, Li X, Xiang $K, M a L, H u X Y$, Yang Y. Transcriptome analysis reveals diversified adaptation of Stipa purpurea along a drought gradient on the Tibetan Plateau. Funct Integr Genom. 2015;15:295-307.

14. Yi YJ, Cheng X, Yang ZF, Zhang SH. MaxEnt modeling for predicting the potential distribution of endangered medicinal plant (H. riparia Lour) in Yunnan, China. Ecol Eng. 2016;92:260-9.

15. Anderson OF, Guinotte JM, Rowden AA, Tracey DM, Mackay KA, Clark MR. Habitat suitability models for predicting the occurrence of vulnerable marine ecosystems in the seas around New Zealand. Deep Sea Res Part I Oceanogr Res Pap. 2016;115:265-92.

16. Elith J, Leathwick JR. Species distribution models: ecological explanation and prediction across space and time. Annu Rev Ecol Evol Syst. 2009:40:677-97.

17. Guisan A, Thuiller W. Predicting species distribution: offering more than simple habitat models. Ecol Lett. 2005:8:993-1009.

18. Wisz MS, Pottier J, Kissling WD, Pellissier L, Lenoir J, Damgaard CF, Dormann CF, Forchhammer MC, Grytnes JA, Guisan A, Heikkinen RK, Hoye TT, Kuhn I, Luoto M, Maiorano L, Nilsson MC, Normand S, Ockinger E, Schmidt NM, Termansen M, Timmermann A, Wardle DA, Aastrup P, Svenning JC. The role of biotic interactions in shaping distributions and realised assemblages of species: implications for species distribution modelling. Biol Rev Camb Philos Soc. 2013;88:15-30.

19. Gilman SE, Urban MC, Tewksbury J, Gilchrist GW, Holt RD. A framework for community interactions under climate change. Trends Ecol Evol. 2010;25:325-31.

20. Cheung WWL, Lam VWY, Sarmiento JL, Kearney K, Watson R, Pauly D. Projecting global marine biodiversity impacts under climate change scenarios. Fish Fish. 2009;10:235-51.

21. Hermoso V, Kennard MJ, Linke S, Pearson R. Assessing the risks and opportunities of presence-only data for conservation planning. J Biogeogr. 2015;42:218-28.

22. Phillips SJ, Dud'k M, Schapire RE. A maximum entropy approach to species distribution modeling. Proceedings of the Twenty-First International Conference on Machine Learning. 2004; 83: 655-662.

23. Busby JR. BIOCLIM: a bioclimate analysis and prediction system. Plant Prot Q. 1991;6:8-9.

24. Carpenter G, Gillison AN, Winter J. DOMAIN: a flexible modelling procedure for mapping potential distributions of plants and animals. Biodivers Conserv. 1993;2:667-80.

25. Yee TW, Mitchell ND. Generalized additive models in plant ecology. J Veg Sci. 2002;157:141-56.

26. Lehmann A, Overton JM, Leathwick JR. Erratum to "GRASP: generalized regression analysis and spatial prediction". Ecol Model. 2002;157:189-207.

27. Hirzel A, Guisan A. Which is the optimal sampling strategy for habitat suitability modelling. Ecol Model. 2002;157:331-41.

28. Phillips SJ, Anderson RP, Schapire RE. Maximum entropy modeling of species geographic distributions. Ecol Model. 2006;190:231-59.

29. Ni J. A simulation of biomes on the Tibetan Plateau and their responses to global climate change. Glob Ecol Biogeogr. 2000;20:80-9.

30. Yue PP, Lu XF, Ye RR, Zhang CX, Yang SB, Zhou YB, Peng M. Distribution of Stipa purpurea steppe in the Northeastern Qinghai-Xizang Plateau (China). Rus J Ecol. 2011:42:50-6.

31. IPOC. Towards New Scenarios for Analysis of Emissions, Climate Change, Impacts, and Response Strategies. Environ Policy Collect. 2008;5(5):399-406.

32. Vuuren DPV, Edmonds J, Kainuma M, Kainuma M, Riahi K, Thomson A, Hibbard K, Hurtt GC, Kram T, Krey V, Lamarque JF, Masui T, Meinshausen M, Nakicenovic N, Smith SJ, Rose SK. The representative concentration pathways: an overview. Clim Change. 2009;109:5-31. https://doi. org/10.1007/s10584-011-0148-z.

33. Weyant J, Azar C, Kainuma M, Kejun J, Nakicenovic N, Shukla PR, La Rovere E, Yohe G. Report of 2.6 Versus 2.9 Watts $/ \mathrm{m}^{2}$ RCPP evaluation panel. Geneva: IPCC Secretariat; 2009.

34. R Development Core Team R: A language and environment for statistical computing, R Foundation for Statistical Computing, Vienna, Austria, ISBN.2011;3-900051-07-0. http://www.Rproject.org/. Accessed 20 May 2015.
35. Jaynes ET. Information theory and statistical mechanics. Phys Rev. 1957;106:620-30

36. Phillips SJ, Dudík M, Schapire RE. Modeling of species distributions with MaxEnt: newextensions and a comprehensive evaluation. Ecography. 2008;31:161-75.

37. Jennie P, Ferrier S. Evaluating the predictive performance of habitat models developed using logistic regression. Ecol Model. 2000;133(3):225-45.

38. Araújo MB, Pearson RG, Thuiller WM. Validation of species-climate impact models under climate change. Glob Change Biol. 2005;11:1504-13.

39. Muscarella R, Galante PJ, Soley-Guardia M, Boria RA, Kass JM, Uriarte M, Anderson RP. ENMeval: an R package for conducting spatially independent evaluations and estimating optimal model complexity for MaxEnt ecological niche models. Methods Ecol Evol. 2014;5:1198-205.

40. Hanley JA, MCNeil BJ. The meaning and use of the area under a receiver operating characteristic (ROC) curve. Radiology. 1982;143:29-36.

41. Radosavljevic A, Anderson RP, Araújo M. Making better MaxEnt models of species distributions: complexity, overfitting and evaluation. J Biogeogr. 2013:41:629-43.

42. Shcheglovitova M, Anderson RP. Estimating optimal complexity for ecological niche models: a jackknife approach for species with small sample sizes. Ecol Model. 2013;269:9-17.

43. Qian SS. Environmental and Ecological Statistics with R. Chapman and Hall/CRC. Appl Environ Stat. 2010;324(2):117-54.

44. Zhong L, Ma YM, Salama MS, Su Z. Assessment of vegetation dynamics and their response to variations in precipitation and temperature in the Tibetan Plateau. Clim Change. 2010;103(3-4):519-35.

45. Wang J, Wang Z, Zhang X, Zhang Y, Ran C, Zhang J, Chen B, Zhang B. Response of Kobresia pygmaea and Stipa purpurea Grassland communities in Northern Tibet to nitrogen and phosphate addition. Mt Res Dev. 2015;35:78-86.

46. Wang T, Yu D, Li J, Ma K. Advances in research on the relationship between climatic change and tree-ring width. Acta Phytoecologica Sinica. 2003;27:23-33.

47. Zhu JK. Salt and drought stress signal transduction in plants. Annu Rev Plant Biol. 2002;53:247-73.

48. Yang H, Haiyan BU, Wenjing GE, Wang X, Xia Y, Bing MA. The relationship between seed size and main reserve contents of seeds in 41 Asteraceae species of alpine meadow in the northeastern Qinghai Tibet Plateau. Chin J Ecol. 2016;35:2299-312.

49. Kelly MR. Seed size in tropical trees: aomparative study of factors affecting seed size in Peruvian angiosperms. Oecologia. 1995;102:377-88.

50. Zhang H, Wang XP, Zhang YF, Hu R, Pan YX, Chen N. Responses of plant growth of different life forms to rainfall amount changes in an arid desert area. Chinese Journal of Ecology. 2015;34:1847-53.

51. Zhang HY, Fan JW, Shao QQ, Zhang YX. Ecosysytem dynamics in the 'Returning Rangeland to Grassland' programs, China. Acta Prataculturae Sinica. 2016;25(4):1-15.

52. Cao M, Prince SD, Small J, Goetz SJ. Remotely sensed interannual variations and trends in terrestrial net primary productivity 1981-2000. Ecosystems. 2004;7:233-42.

53. Yang YH, Piao SL. Variations in grassland vegetation cover in relation to climatic factors on the Tibetan Plateau. J Plant Ecol. 2006;30:1-8.

54. Xu MH, Xue X. A research on summer vegetation characteristics and short-time responses to experimental warming of alpine meadow in the Qingha-Tibetan Plateau. Acta Ecol Sin. 2013;33:2071-83.

55. Xu MH, Xue X. Analysis on the effects of climate warming on growth and phenology of alpine plants. J Arid Land Resour Environ. 2013;27:137-41.

56. Duan M, Gao Q, Wan Y, Yue LI, Guo Y, Luobu D. Effect of grazing on community characteristics and species diversity of Stipa purpurea alpine grassland in Northern Tibet. Acta Ecol Sin. 2010;30:3892-900.

57. Shang ZH, Ma YS, Long RJ, Ding LM. Effect Of fencing, artificial seeding and abandonment on vegetation composition and dynamics of 'black soil land'in the headwaters of the Yangtze and the Yellow Rivers of the Qinghai-Tibetan Plateau. Land Degrad Dev. 2008;19:554-63.

58. Yan Z, Wu XP, He XH, Zhang HM, Gong FF, Cai DX, Zhu P, Gao HJ. Basic soil productivity of spring maize in black soil under long-term fertilization based on DSSAT model. J Integr Agric. 2014;13:577-87.

59. Zhao QF, Wang G, Li QX, Ma SR, Cui Y, Michael G. Genetic diversity of five Kobresia species along the eastern Qinghai-Tibet Plateau in China. Hereditas. 2006;143:33-40. 